\title{
Caracterização microclimática em cultivo consorciado café/banana ${ }^{1}$
}

\author{
José R. M. Pezzopane ${ }^{2}$, Mário J. Pedro Jr. ${ }^{3,5}$ \& Paulo B. Gallo ${ }^{4}$ \\ RESUMO
}

cafeeiros (Coffea arabica L.) cv. Icatu Vermelho IAC 4045, cultivados a pleno sol e consorciados com bananeira (Musa sp AAB) 'Prata Anã', em Mococa, SP ( $21^{\circ} 28^{\prime}$ S, 47 $01^{\circ}$ ' W, altitude $665 \mathrm{~m}$ ), entre outubro de 2001 e setembro de 2002. Os elementos foram monitor ados em um ponto do cultivo a pleno sol e em dois pontos do cultivo consorciado, sendo um próximo à planta de banana e outro situado em uma condição central, entre as plantas de banana. Os resultados obtidos mostrar am que o cultivo consorciado de café promoveu atenuação dos valores médios da radiação solar global, tendo sido mais evidente no ponto amostral situado próximo às bananeiras. Verificou-se, ainda, uma redução média de $48 \%$ na velocidade do vento no cultivo consorciado, influenciada pela época do ano, além do desbaste das bananeiras. Com relação à temperatura e umidade do ar, foram encontradas diferenças apenas na temperatura máxima no ponto central da parcela do cultivo consorciado que, por sua vez, apresentou médias super iores em relação ao cultivo a pleno sol no verão e outono e em relação ao ponto situado próximo às bananeiras na primavera, ver ão e outono; essas diferenças foram mais significativas em dias com condição ens olarada e de pouca ocorrência de vento.

Palavras-chave: microclima, Coffea arabica, radiação solar global, temperatur a do ar, consorciação

\section{Microclimatic characterization in coffee and banana intercrop}

\begin{abstract}
Microclimatic meas urements (solar radiation, wind s peed, air temperature and relative humidity) were taken on a daily and hourly basis, from October, 2001 to September, 2002 in a coffee crop ( Coffea arabica L.) cv. Icatu Verrmelho IAC 4045, grown in two different conditions: shaded by banana ( Musa sp AAB) 'Prata Anã' and unshaded. The experiment was carri ed out at Mococa, São Paulo State, Brazil (21 $21^{\circ} \mathrm{S}, 47^{\circ} 01^{\prime} \mathrm{W}$, altitude $\left.665 \mathrm{~m}\right)$. The micr oclimatic measurements were taken in one position of the unshaded coffee crop and in two different pos itions of the shaded coffee crop the first being close to the nearest point to banana plants and the second at the center of the shaded crop plot. The banana plants reduced the incoming solar radiation to the coffee crop, showing a higher reduction at the nearest point to banana plants. The wind speed was reduced by $48 \%$ at the shaded crop, this value being influenced by the seas on of the year and pruning of the banana plants. Differ ences were found only for the maximum air temperature at the central point of the shaded crop, showing higher aver ages in relation to the uns haded crop during the summer and autumn, and also in relation to the nearest point to banana plants during the spring, summer and autumn, showing higher differences on sunny days and with low wind speed.
\end{abstract}

Key words: microclimate, Coffea arabica, solar radiation, air temperature, intercr op

\footnotetext{
2 Extraído da Tese de Doutorado do primeiro autor apresentada à Escola Superior de Agricultura "Luiz de Queiroz" , Piracicaba, SP

${ }^{2}$ Centro Universitário Norte do Es pírito Santo/UFES, Rua Humberto de Almeida Franklin 257, Bairro Universitário, CEP 29933-480, São Mateus, ES. Fone: (27) $3763-8650$. E-mail: josepezzopane@ceunes.ufes.br

3 Instituto Agronômico de Campinas - IAC/APTANS AA, CP 28, CEP 13001-970, Campinas, SP. Fone: (19) 3241 5188. E-mail: mpedro@iac.sp.gov.br

${ }^{4}$ Departamento de Descentralizaçãodo Desenvolvimento/APTA, CP 58, CEP 13730-970, Mococa, SP. Fone: (19) 3656-0200. E-mail: polonordestepaulistz@aptaregional.sp.gov.br

Com Bolsa de Produtividade em Pesquisa - CNPq
} 


\section{INTRODUÇÃO}

No Brasil, o cultivo do café arábica se desenvolveu extensivamente em ambiente a pleno sol, apresentando cultivares selecionadas para alta produtividade, desde que se faça uso intensivo de insumos, conduzidas em monocultivo, de composição homogênea, com inexistência de mecanismos de auto-regulação e equilíbrio. Esse tipo de exploração proporcionou, em algumas regiões, caráter nômade da cafeicultura apresentando, como principais problemas, a baixa produtividade, lavouras decadentes e alto custo de produção, agravados por condições climáticas extremas, como ocorrência de geadas e secas prolongadas.

A proposta de cultivos arborizados por meio do sombreamento moderado visa atenuar os efeitos de condições climáticas extremas e proporcionar maior sustentabilidade aos sistemas. Neste contexto se acrescenta ainda, a agregação de uma fonte de renda extra para os cafeicultores (Vaast et al., 2004) e melhor aproveitamento da mão-de-obra disponível, benefício de grande importância para a agricultura familiar. Com esta análise é possível verificar o enorme potencial para a utilização da técnica de consorciação, principalmente em áreas de pequena extensão, visando auxiliar na melhoria da produtividade e sustentabilidade da produção.

Dentre as plantas que estão sendo utilizadas no Brasil para arborização de cafezais, podem ser citadas a grevílea (Baggio et al., 1997), seringueira (Matiello \& Almeida, 1991) e cajueiro (Matiello et al., 1989). Entre essas espécies o uso de frutíferas com alto valor de mercado e boas características para a arborização, como o coqueiro anão, a pupunha e bananeira, podem ser boas opções (Caramori \& Manetti Filho, 1993).

O estudo das interações microclimáticas entre os componentes de um agrossistema e o ambiente, além da análise de crescimento e dos fatores de produção, são critérios básicos para as definições da viabilidade de cultivos consorciados na agricultura. A grandeza das modificações microclimáticas ocorridas em um cultivo consorciado depende do tipo de árvore de cobertura e conseqüentemente, da área foliar, estação do ano, hora do dia e do ponto de amostragem dos elementos microclimáticos (Brenner, 1996).

Observações microclimáticas em cultivos arborizados de café já foram realizadas em diferentes regiões e situações de cultivo, como em sistemas agroflorestais (Barradas \& Fanjul, 1986; Vaast et. al., 2004), arborização com grevílea (Miguel et al.,1995) e consorciação com coqueiro-anão verde (Pezzopane et al., 2003). Esses trabalhos evidenciam que a variabilidade temporal e espacial da temperatura e umidade do ar em um sistema consorciado e suas diferenças em relação a um cultivo a pleno sol, vão depender do tipo de copa da árvore utilizada e da densidade do sombreamento.

Considerando esses aspectos e aliado à necessidade de informações a respeito da caracterização microclimática de cultivos, o presente trabalho foi realizado com o objetivo avaliar as condições microclimáticas em cultivo de café a pleno sol e consorciado com banana 'Prata Anã'.

\section{MATERIAL E MÉTODOS}

Realizaram-se observações microclimáticas durante os meses de outubro de 2001 a setembro de 2002, em um sistema de produção consorciado de café (Coffea arabica L.) cv. Icatu Vermelho IAC 4045 enxertado sobre cv. Apoatã IAC 2258, com três anos de idade, conduzido a pleno sol e consorciado com banana (Musa spp AAB) 'Prata Anã', em Mococa, SP $\left(21^{\circ} 28^{\prime} \mathrm{S}, 47^{\circ} 01^{\prime} \mathrm{W}\right.$, altitude $\left.665 \mathrm{~m}\right)$.

Nos dois sistemas de cultivo, o espaçamento das plantas de café era de $4 \times 1 \mathrm{~m}$ e altura aproximada de $1,8 \mathrm{~m}$, sendo que as bananeiras possuíam espaçamento de $8 \times 8 \mathrm{~m}$ altura aproximada de $4,5 \mathrm{~m}$, totalizando 156 plantas por ha (Figura 1, esquerda). Os sistemas de produção constituíam parcelas de $40 \times 40 \mathrm{~m}$, em mesma condição topográfica e de orientação de encosta (nordeste), com baixa declividade.

A condução da cultura do café foi realizada com os tratos culturais, de acordo com as instruções técnicas para a região (Thomaziello et al., 2000) e, para a cultura da bananeira, seguiram-se as recomendações de Moreira (1987). Nas bananeiras, ressalta-se a técnica do desbaste (20/12/2001 e 08/ 03/2002), para favorecer o maior desenvolvimento e produção da planta, eliminando-se das plantas que já produziram e os excessos de brotação para as produções seguintes.

A caracterização microclimática constitui-se em avaliações de radiação solar global, medida com tubos solarímetros (TSL, Delta T Devices), instalados acima do dossel da cultura de café $(1,9 \mathrm{~m})$; de temperatura do ar e umidade relativa do ar, determinadas com conjunto psicrométrico (Vaisala, HMP 45C), protegidos com abrigo micrometeorológico, constituídos de doze pratos plásticos sobrepostos (RM YOUNG, Gill), instalados na altura do dossel das plantas de café e da velocidade do vento, obtida com anemômetros (RM YOUNG, 03001-L), instalados a $2 \mathrm{~m}$ de altura. Para melhor representar as condições microclimáticas do cultivo consorciado, instalaram-se sensores em dois pontos da lavoura: um em uma condição próxima às bananeiras (Ponto 1 ) e outro em um ponto central (Ponto 2) da parcela (Figura 1, esquerda).

Os sensores foram acoplados a um sistema automático de aquisição de dados (Campbell Scientific Inc., CR10X),

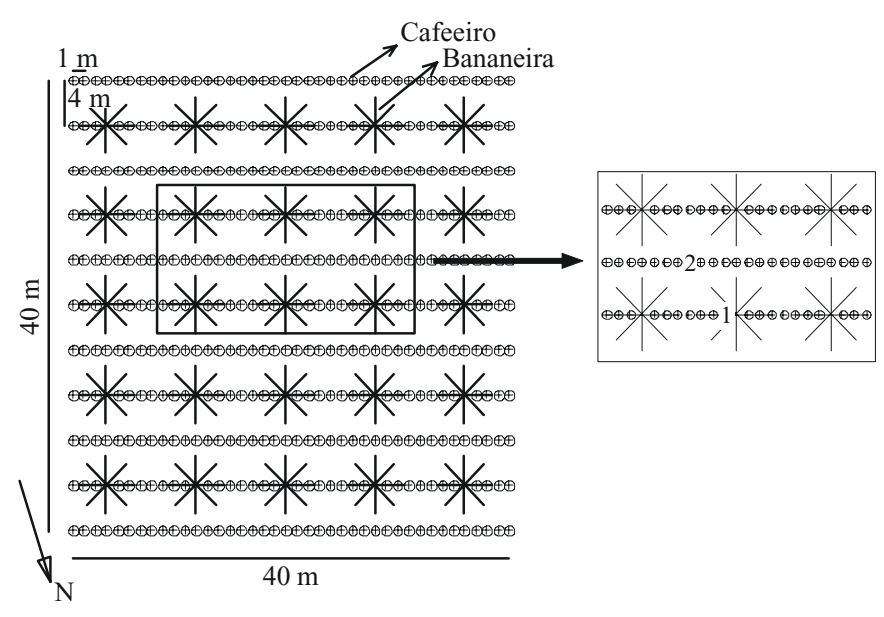

Figura 1. Representação esquemática de instalação de sensores na parcela consorciada 
programado para leituras a cada $20 \mathrm{~s}$, médias a cada $15 \mathrm{~min}$ e obtenção dos valores médios diários da umidade relativa do ar e velocidade do vento, extremos diários da temperatura e integração diária da radiação solar global.

Visando possibilitar comparação, as avaliações microclimáticas foram realizadas simultaneamente no centro da parcela de café cultivada a pleno sol, em que os sensores de temperatura do ar e umidade relativa do ar e velocidade do vento, foram instalados na mesma altura que o do sistema consorciado.

Utilizaram-se dados meteorológicos da Estação meteorológica automática, pertencente ao Polo Regional de Desenvolvimento Tecnológico dos Agronegócios do Nordeste Paulista, em Mococa, situada a aproximadamente $500 \mathrm{~m}$ do experimento, para a representação da radiação solar global no cultivo a pleno sol e com o objetivo de subsidiar a discussão dos resultados obtidos.

Para complementar a discussão sobre o comportamento da umidade atmosférica, calcularam-se a pressão de saturação e a pressão atual de vapor, visando à obtenção do déficit de pressão de vapor (diferença entre a pressão de saturação e a pressão atual de vapor) segundo as equações utilizadas por Pereira et al. (1997).

As médias por estação do ano dos dados diários dos elementos temperatura do ar (valores máximos e mínimos); umidade relativa do ar; pressão atual de vapor e velocidade do vento, foram submetidos ao teste $t$ (Vieira, 1980) para médias com variâncias equivalentes, adotando-se os níveis de 5 e $1 \%$ de probabilidade, para detectar diferenças entre os pontos amostrais.

\section{RESULTADOS E DISCUSSÃO}

A Figura 2 apresenta o resumo das condições meteorológicas ocorridas durante o período experimental (Figura 2A),
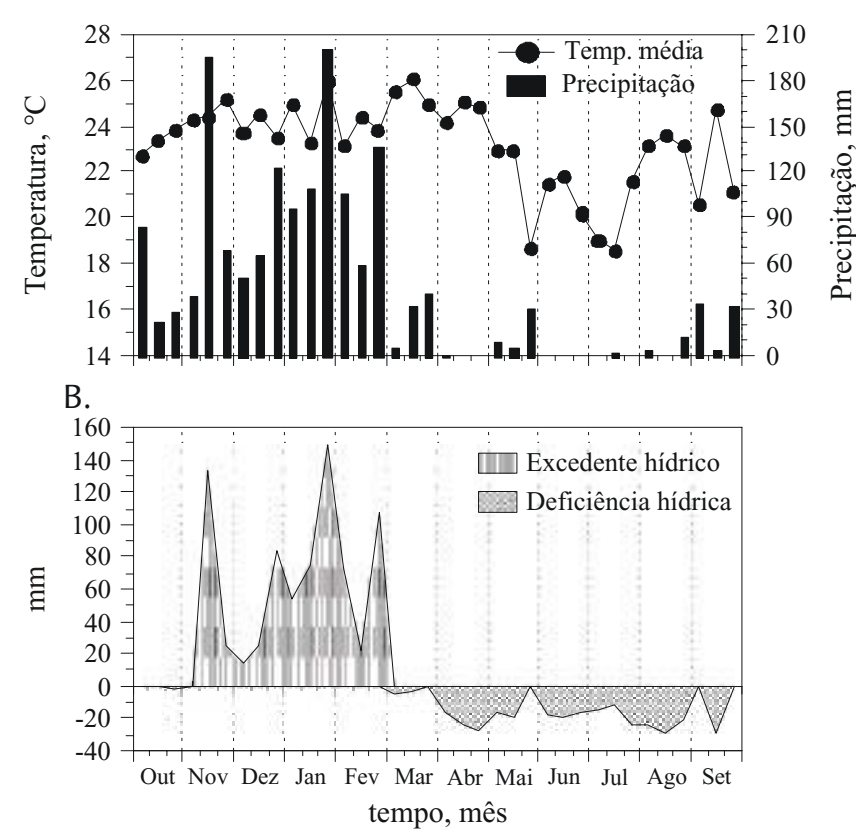

Figura 2. Variação decendial da temperatura média do $\operatorname{ar}\left({ }^{\circ} \mathrm{C}\right)$ e da precipitação pluvial $(\mathrm{mm})(\mathrm{A})$ e extrato do balanço hídrico $(\mathrm{CAD}=100 \mathrm{~mm})$ (B) no período de outubro de 2001 a setembro de 2002, em Mococa, SP e o extrato do balanço hídrico (Figura 2B), segundo Camargo \& Camargo (1993), relativo ao período de outubro de 2001 a setembro de 2002 .

O ano agrícola do período experimental (2001-2002) apresentou o início das chuvas em setembro, com ocorrência de excedentes hídricos a partir de novembro. Até o início do mês de março de 2002, o período chuvoso apresentou elevados excedentes hídricos (cerca de $700 \mathrm{~mm}$ ), temperaturas amenas e alta umidade relativa do ar. A partir de março de 2002, iniciou-se um período de deficiência hídrica, sendo que o mês de abril de 2002 apresentou elevados valores de temperatura máxima (valor médio mensal de $32,2^{\circ} \mathrm{C}$ ) e praticamente ausência de chuvas, quando se iniciou o período seco, que perdurou até o final do mês de outubro de 2002 (Figura 2B), embora se tenha verificado ocorrência de chuvas durante o mês de maio (44 mm), no início e final do mês de setembro.

\section{Radiação solar global}

A incidência média horária da radiação solar global (RG) no cultivo a pleno sol durante os meses de outubro de 2001 a setembro de 2002, representada pelas medições realizadas no posto meteorológico e a transmissão da radiação nos pontos 1 e 2 do cultivo consorciado estão apresentadas na Figura 3. A incidência média mensal da radiação solar global (Figura 3A), assim como a transmissividade dos dois pontos amostrais do sistema consorciado (Figura 3B e 3C), para o período entre 7 e $18 \mathrm{~h}$ entre os meses de outubro de 2001 e setembro de 2002, foram interpoladas através do método da krigagem.

Durante o período de medidas a incidência média mensal da $\mathrm{RG}$ variou de $100 \mathrm{~W} \mathrm{~m}^{-2}$ nas primeiras horas da manhã (período de fevereiro a setembro) até cerca de $800 \mathrm{~W} \mathrm{~m}^{-2}$ ao meio dia (março e abril - Figura 3A). Apesar dos meses de dezembro e janeiro apresentarem maior potencial de incidência de RG ao meio-dia, o excesso de dias chuvosos (Figura 2A) neste período fez com que maior incidência de RG ocorresse nos meses de março e abril, época do ano caracterizada pela ausência de chuvas (Figura 2).

Analisando-se a transmissividade da RG no ponto amostral do cultivo consorciado situado próximo à planta de banana (Figura 3B), pode-se verificar maiores transmissões no período de outono-inverno nas primeiras horas da manhã, até cerca de $10 \mathrm{~h}$. Nas horas centrais do dia ocorreu diminuição da transmissão, sendo que no período de abril a julho, entre as 13 e $15 \mathrm{~h}$, esses valores atingiram cerca de $20 \%$, mostrando um efeito protetor das folhas de bananeira sobre as plantas de café.

No ponto central da parcela consorciada (Figura 3C), a transmissão foi mais elevada, mantendo, entre as 10 e $15 \mathrm{~h}$, valores sempre superiores a $90 \%$, principalmente nos meses de dezembro a junho; de maneira geral, a transmissão neste ponto ficou acima dos $80 \%$, à exceção nas horas iniciais do dia no período de outono-inverno e ao final da tarde, a partir do mês de março devido, provavelmente, ao sombreamento provocado por folhas de bananeiras adjacentes ao ponto de medida. 

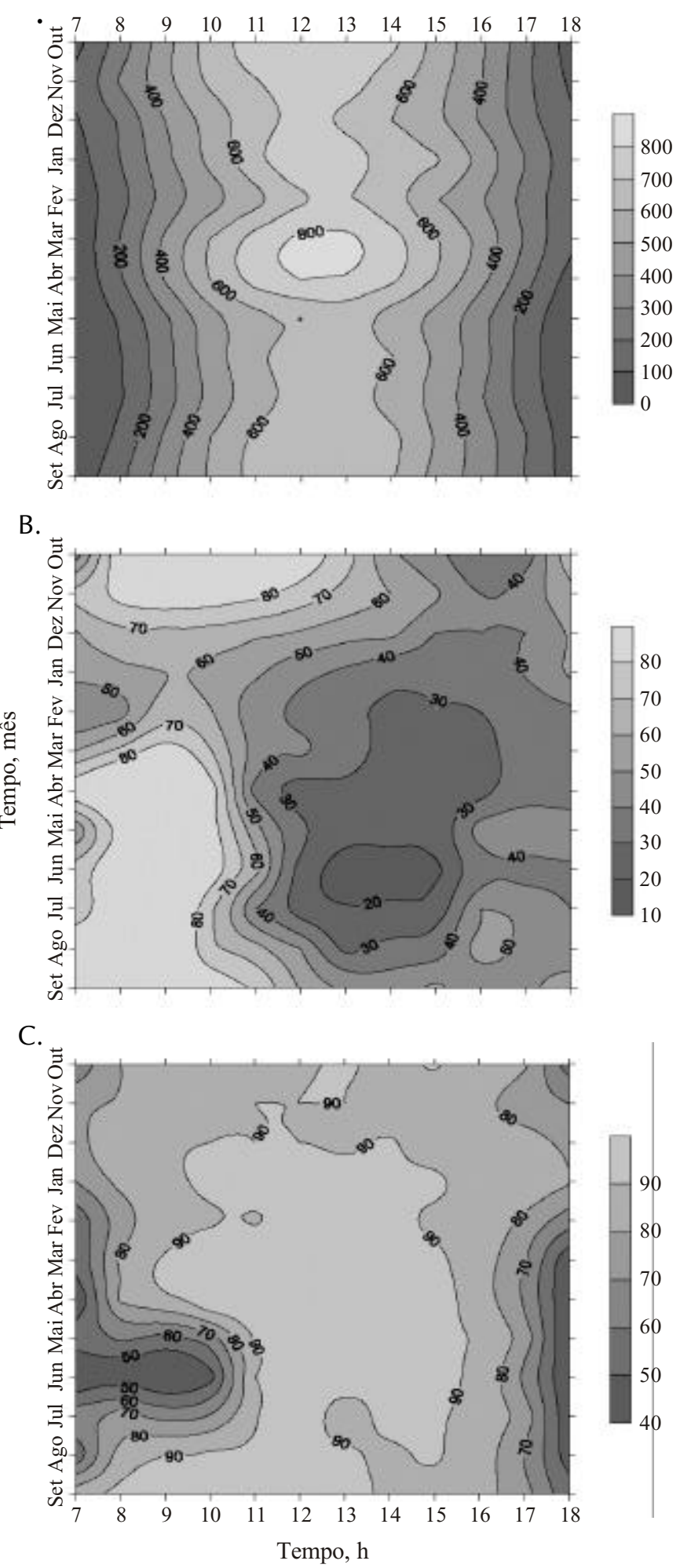

Figura 3. Isolinhas da incidência da radiação solar global $\left(\begin{array}{ll}W & \end{array}{ }^{2}\right.$ (A) e transmissividade em cultivo cons orciado (Ponto 1-B e Ponto 2-C) entre as 7 e 18 h durante o período de outubro de 2001 a setembro de 2002, em Mococa, SP.

\section{Velocidade do vento}

Os valores médios da velocidade do vento para o sistema de produção de café a pleno sol e o consorciado com bananeira 'Prata Anã' por estação do ano e os valores do teste t de comparação de médias, estão apresentados na Tabela 1.
Tabela 1. Médias da velocidade do vento ( $\mathrm{m} s$ ) e valores do testet de comparação de médias, em cultivo de café a pleno sol (PS) e em diferentes pontos amostrais de cultivo café cons orciado com bananeira 'Prata Anã', em Mococa, SP, avaliadas em quatro estações do ano

\begin{tabular}{|c|c|c|c|c|c|c|}
\hline \multirow{3}{*}{ Época } & \multicolumn{3}{|c|}{ Vento $\left(\mathrm{m} \mathrm{s}^{-1}\right)$} & \multicolumn{3}{|c|}{ Valor de $\mathrm{t}$} \\
\hline & \multirow{2}{*}{ PS } & \multicolumn{2}{|c|}{ Consorciado } & \multirow{2}{*}{ PS-P1 } & \multirow{2}{*}{ PS-P2 } & \multirow{2}{*}{ P1-P2 } \\
\hline & & P1 & P2 & & & \\
\hline Primavera & 1,33 & 0,60 & 0,58 & $10,02^{\star \star}$ & $11,85^{\star *}$ & $0,27^{\text {ns }}$ \\
\hline Verão & 1,02 & 0,48 & 0,49 & $12,30^{\text {** }}$ & $12,62^{* *}$ & $0,21^{\mathrm{ns}}$ \\
\hline Outono & 0,79 & 0,48 & 0,40 & $8,91^{* *}$ & 12,01 ** & $2,88^{* \star}$ \\
\hline Inverno & 1,08 & 0,70 & 0,67 & $5,80^{\star *}$ & $6,45^{\star *}$ & $0,67^{\text {ns }}$ \\
\hline
\end{tabular}

ns Não-significativo; ** Significativo a $1 \%$ de probabilidade

As diferenças entre os valores médios da velocidade do vento foram significativas pelo teste $t$, para os dois pontos amostrais do sistema consorciado em todas as épocas do ano em relação à incidência no cultivo a pleno sol. Com relação à variabilidade espacial dentro do sistema consorciado, as menores médias, para todas as épocas do ano, com exceção do verão, foram obtidas no ponto 2 de amostragem, sendo verificando-se diferença significativa entre os pontos amostrais do sistema consorciado para o período de outono devido, provavelmente, à predominância de vento do sentido nordeste, que ocorre na região.

As médias quinquidiais da velocidade do vento para os dois sistemas de produção, estão apresentadas na Figura 4. Ressalta-se que os valores obtidos no sistema consorciado são relativos à média de dois sensores instalados na parcela.

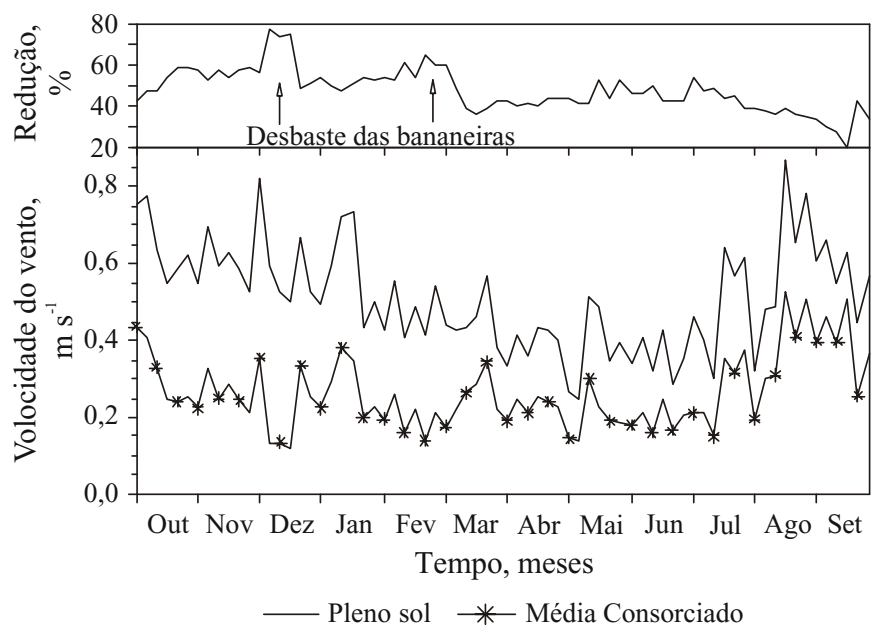

Figura 4. Médias quinquidiais da velocidade do vento $\left(\mathrm{m} \mathrm{s}^{-1}\right)$ em cultivos de café a pleno sol e cons orciado com banana 'Prata Anã', em Mococa, SP

A redução da velocidade do vento promovida pelas bananeiras durante os meses do ano, variou de 21 a $79 \%$ em relação ao cultivo a pleno sol (Figura 4), com média anual de $48 \%$, sendo mais significativa no período de outubro de 2001 a fevereiro de 2002 devido, provavelmente, ao maior enfolhamento da bananeira nesses meses. Também se nota que o desbaste das bananeiras, ocorrido no final de dezembro e início de março (Figura 4) alterou os valores da redução dos dois parâmetros nos períodos subseqüentes, fazendo com que as reduções fossem um pouco menores durante o período de outono e de inverno. 
Pezzopane et al. (2003) constataram reduções superiores a $60 \%$ na incidência de vento em um sistema consorciado de café com coqueiro anão verde. Camargo \& Pereira (1994), relatam que um dos maiores benefícios do cultivo consorciado de café é a redução da incidência de ventos, o que causa danos físicos às folhas e reduz seu crescimento (Caramori et al., 1986).

\section{Temperatura do ar}

Os valores médios de temperatura máxima, mínima e média do ar para o sistema de produção de café a pleno sol e o consorciado com bananeira 'Prata Anã' por estação do ano estão apresentados na Tabela 2 .

Tabela 2. Médias das temperaturas máxima, mínima e média $\left({ }^{\circ} \mathrm{C}\right)$ e valores do teste tde comparação de médias, em cultivo de caféa pleno sol e em diferentes pontos amostrais de cultivo café consorciado com bananeira 'Prata Anã', em Mococa, SP

\begin{tabular}{|c|c|c|c|c|c|c|}
\hline \multirow{2}{*}{ Época } & \multirow{2}{*}{$\begin{array}{c}\text { Pleno } \\
\text { sol }\end{array}$} & \multicolumn{2}{|c|}{ Consorciado } & \multicolumn{3}{|c|}{ Valor de $\mathrm{t}$} \\
\hline & & P1 & P3 & 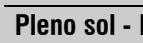 & Pleno sol - $\mathrm{P}$ & P1 - P3 \\
\hline & \multicolumn{6}{|c|}{ Temperatura Máxima $\left({ }^{\circ} \mathrm{C}\right)$} \\
\hline Primavera & 30,7 & 30,4 & 31,5 & $0,59^{\text {ns }}$ & $1,49^{\text {ns }}$ & $2,07^{*}$ \\
\hline Verão & 31,7 & 31,1 & 32,7 & $1,39^{\text {ns }}$ & $2,14^{*}$ & $3,14^{* *}$ \\
\hline Outono & 30,9 & 31,0 & 32,5 & $0,27^{\text {ns }}$ & $3,50^{\star *}$ & $3,30^{* *}$ \\
\hline \multirow[t]{2}{*}{ Inverno } & 29,6 & 29,8 & 29,9 & $0,37^{\text {ns }}$ & $0,92^{\text {ns }}$ & $0,56^{\mathrm{ns}}$ \\
\hline & \multicolumn{6}{|c|}{ Temperatura Mínima $\left({ }^{\circ} \mathrm{C}\right)$} \\
\hline Primavera & 18,0 & 18,1 & 17,9 & $0,37^{\mathrm{ns}}$ & $0,35^{\text {ns }}$ & $0,71^{\text {ns }}$ \\
\hline Verão & 19,1 & 19,4 & 19,1 & $0,98^{\text {ns }}$ & $0,34^{\mathrm{ns}}$ & $0,66^{\mathrm{ns}}$ \\
\hline Outono & 15,7 & 16,0 & 15,7 & $0,57^{\mathrm{ns}}$ & $0,02^{\text {ns }}$ & $0,55^{\mathrm{ns}}$ \\
\hline \multirow[t]{2}{*}{ Inverno } & 14,3 & 14,4 & 14,3 & $0,25^{\text {ns }}$ & $0,10^{\text {ns }}$ & $0,15^{\mathrm{ns}}$ \\
\hline & \multicolumn{6}{|c|}{ Temperatura Média $\left({ }^{\circ} \mathrm{C}\right)$} \\
\hline Primavera & 23,5 & 23,5 & 23,6 & $0,28^{\text {ns }}$ & $0,62^{\text {ns }}$ & $0,35^{\text {ns }}$ \\
\hline Verão & 24,0 & 24,1 & 24,3 & $0,27^{\mathrm{ns}}$ & $1,31^{\mathrm{ns}}$ & $1,07^{\mathrm{ns}}$ \\
\hline Outono & 22,4 & 22,5 & 22,7 & $0,45^{\text {ns }}$ & $1,01^{\mathrm{ns}}$ & $0,58^{\mathrm{ns}}$ \\
\hline Inverno & 21,1 & 21,2 & 21,3 & $0,28^{\text {ns }}$ & $0,53^{\text {ns }}$ & $0,26^{\mathrm{ns}}$ \\
\hline
\end{tabular}

ns Não-significativo; * $\mathrm{e}{ }^{* *}$ Significativo a 5 e a $1 \%$ de probabilidade, respectivamente

Os valores médios por estação do ano, da temperatura máxima, obtidos no ponto 1 (próximo às plantas de bananeira) do sistema consorciado, não apresentaram diferenças significativas pelo teste $\mathrm{t}$ quando comparados com os valores obtidos no cultivo a pleno sol, sendo menores na primavera $\left(30,7^{\circ} \mathrm{C}\right.$ no cultivo a pleno sol e $30,4{ }^{\circ} \mathrm{C}$ no ponto 1$)$ e verão $\left(31,7^{\circ} \mathrm{C}\right.$ no cultivo a pleno sol e $31,1^{\circ} \mathrm{C}$ no ponto 1$)$, e ligeiramente superiores no outono-inverno $\left(0,1\right.$ e $0,2{ }^{\circ} \mathrm{C}$, respectivamente). Quando o cultivo de café ocorre em condições de sombreamento elevado, como apresentado por Barradas \& Fanjul (1986) em um sistema agroflorestal de produção de café no México e por Miguel et al. (1995) em um cultivo arborizado de café com grevílea, as diferenças dos valores de temperatura máxima entre o sistema sombreado e o sistema de produção a pleno sol podem atingir até $5,0{ }^{\circ} \mathrm{C}$, com valores inferiores no cultivo sombreado.

Em relação à variação espacial da temperatura máxima do ar dentro do sistema consorciado, pode-se verificar que no ponto de amostragem 2 (ponto central da parcela), os valores médios de temperatura máxima obtidos foram superiores ao cultivo a pleno sol e ao ponto 1 do sistema consor- ciado (Tabela 2), apresentando diferenças significativas no verão e outono. No período de verão a média das temperaturas máximas no ponto 2 do sistema consorciado permaneceu $1,6^{\circ} \mathrm{C}$ acima do ponto 1 do sistema consorciado e $1,0{ }^{\circ} \mathrm{C}$ acima do cultivo a pleno sol, enquanto no outono a média das temperaturas máximas no ponto 2 do sistema consorciado permaneceu cerca de $1,5^{\circ} \mathrm{C}$ superior aos outros dois pontos amostrais.

Ao se analisar as diferenças de temperatura máxima obtidas entre os dois pontos amostrais do sistema consorciado, é imprescindível ressaltar que nos meses de verão e outono ocorreram as maiores interceptações de radiação solar incidente sobre o ponto amostral 1 do sistema consorciado (Figura 3), contribuindo para essas diferenças. Atentando-se as diferenças dos valores de temperatura máxima do ponto 2 do sistema consorciado e o cultivo a pleno sol (Tabela 2), outros componentes do balanço de energia parecem contribuir para valores superiores do ponto central do cultivo consorciado em relação ao cultivo a pleno sol, como a incidência de vento, que foi significativamente menor no centro da parcela consorciada em relação aos outros pontos amostrais, principalmente no outono, quando se detectaram diferenças estatísticas, conforme apresentado na Tabela 1.

Brenner (1996) relata que, em condições de cultivos protegidos por renques ou quebra-ventos, em que a incidência de radiação é semelhante a cultivos desprotegidos, as temperaturas diurnas são superiores em virtude da menor movimentação do ar atmosférico, o que altera o balanço de energia, aumentando o fluxo de calor sensível. Temperaturas diurnas superiores em cultivos protegidos com quebra-ventos, quando a incidência de radiação solar é semelhante a cultivos não protegidos, também foram obtidas por Brown \& Rosemberg (1972), Ujah \& Adeoye (1984), ambos em cultivos protegidos por quebra-ventos artificiais, e Pezzopane et al. (2003), em um sistema de produção de café consorciado com coqueiro-anão verde.

Para melhor representação da sazonalidade das diferenças da temperatura máxima do ar entre os pontos amostrais dos dois sistemas de cultivo, além do efeito de outros elementos em seu comportamento, foram selecionados quatro episódios (Figura 5) sob condição ensolarada, durante o período amostral.

No dia 6/11/2001 (Figura 5A), a temperatura máxima do ar foi $33,4,33,1$ e $33,9^{\circ} \mathrm{C}$ no cultivo a pleno sol e nos pontos amostrais 1 e 2 do cultivo consorciado, respectivamente. Para todo o período diurno a média da velocidade do vento foi de $1,4,0,74$ e $0,60 \mathrm{~m} \mathrm{~s}^{-1}$ no cultivo a pleno sol e nos ponto amostrais 1 e 2 do cultivo consorciado, respectivamente. No dia 16/4/2002, a temperatura máxima do ar foi $32,1,32,8$ e $35,8^{\circ} \mathrm{C}$ no cultivo a pleno sol e nos pontos amostrais 1 e 2 do cultivo consorciado, respectivamente (Figura 5B). Para todo o período diurno, a média da velocidade do vento foi de $1,5,1,0$ e $0,87 \mathrm{~m} \mathrm{~s}^{-1}$ no cultivo a pleno sol e nos ponto amostrais 1 e 2 do cultivo consorciado, respectivamente.

Nos meses de novembro de 2001 e abril de 2002, a transmissão da RG no ponto de amostragem 2 do sistema 

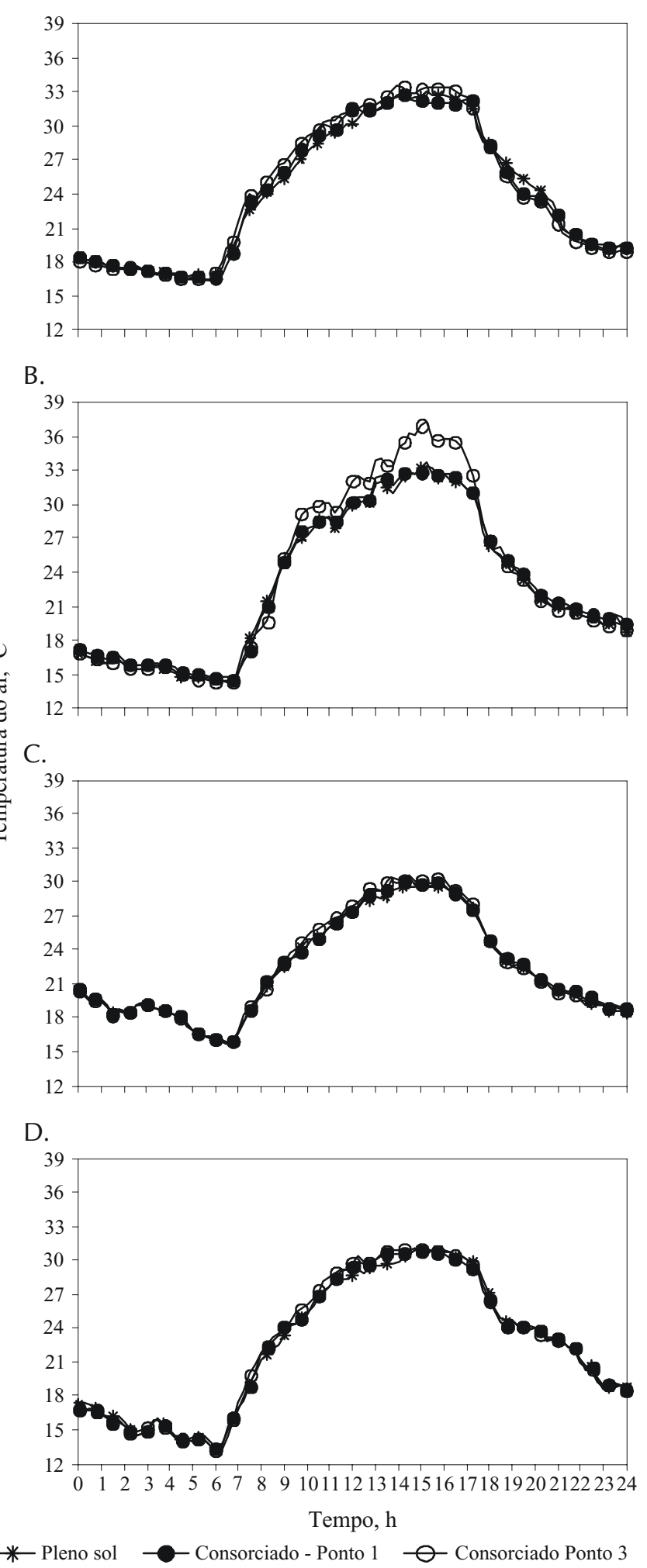

Figura 5. Variação dos valores horários da temperatura do $\operatorname{ar}\left({ }^{\circ} \mathrm{C}\right)$ em cultivo de café a pleno sol e cons orciado com banana 'Prata Anã', em Mococa, SP, nos dias 6/11/2001 (A), 16/4/2002 (B), 18/8/2002 (C) e 27/9/2002 (D)

consorciado foi superior a $90 \%$ nas horas centrais do dia, enquanto no ponto de amostragem 1 , foi de cerca de $60 \%$ (novembro) e 30\% (abril) nas horas centrais do dia.

A variação horária dos valores de temperatura diurna e, conseqüentemente, temperatura máxima, superiores no ponto amostral 2 do sistema consorciado em relação ao sistema de cultivo a pleno sol para os dias 6/11/2001 e 16/4/2002, está associada à incidência de radiação solar global equivalente no período da tarde e à redução da ocorrência de vento verificada entre esses pontos amostrais. Outro fator que pode ter influenciado no aumento da diferença das máximas entre esses pontos amostrais no episódio de 16/4/2002 em relação ao episódio de $6 / 11 / 2001$, foi o acentuado período seco (Figura 2B), fazendo com que aumentasse o fluxo de calor sensível elevando, assim, a temperatura do ar e, por conseqüência, as diferenças entre os pontos amostrais.

No dia 18/8/2002 (Figura 5C), a temperatura máxima do ar foi $30,2,30,6$ e $30,9^{\circ} \mathrm{C}$ no cultivo a pleno sol e nos pontos amostrais 1 e 2 do cultivo consorciado, respectivamente. As plantas de bananeira utilizadas no consórcio promoveram redução de cerca de 30 a $40 \%$ da velocidade do vento, sendo que para todo o período diurno a média da velocidade do vento foi de 2,5, 1,76 e 1,52 $\mathrm{m} \mathrm{s}^{-1}$ no cultivo a pleno sol e nos ponto amostrais 1 e 2 do cultivo consorciado, respectivamente.

No dia 27/9/2002, a temperatura máxima do ar foi 31,3 , 31,1 e $31,3{ }^{\circ} \mathrm{C}$ no cultivo a pleno sol e nos pontos amostrais 1 e 2 do cultivo consorciado, respectivamente (Figura 5D). A incidência da radiação solar global no ponto amostral 2 do sistema consorciado no mês de setembro, sofreu pequena atenuação em relação ao cultivo a pleno sol no período da tarde, enquanto no ponto amostral 1 ocorreu atenuação na transmissividade, que foi mais significativa (Figura 3). As plantas de bananeira utilizadas no consórcio promoveram redução de cerca de $30 \%$ da velocidade do vento no período da tarde, sendo que para todo o período diurno a média da velocidade do vento foi de $1,32,0,88$ e $0,84 \mathrm{~m} \mathrm{~s}^{-1}$ no cultivo a pleno sol e nos pontos amostrais 1 e 2 do cultivo consorciado, respectivamente.

A variação horária dos valores de temperatura diurna e, conseqüentemente temperatura máxima, com valores próximos entre os pontos de amostragem, evidencia a influência de outros elementos na temperatura do ar em sistemas consorciados. No dia 18/8/2002, a velocidade do vento foi elevada em todos os pontos amostrais, com valor médio diurno de $2,5 \mathrm{~m} \mathrm{~s}^{-1}$ no sistema a pleno sol. Embora tenha ocorrido redução da velocidade do vento no sistema consorciado, os valores elevados provocaram homogeneização do ar sobre a cultura, fazendo com que as diferenças entre os pontos amostrais não fossem intensas, apesar do período seco verificado na região (Figura $2 \mathrm{~B}$ ).

Para o episódio de 27/9/2002, um importante fator que influenciou os valores de temperatura, foi a ocorrência de chuvas nos dias anteriores, que alterou o balanço hídrico no último decêndio do mês de setembro (Figura 2B), mudando o comportamento do balanço de energia, aumentando o fluxo de calor latente em relação ao de calor sensível, resultando em efeitos na temperatura do ar.

Quando se analisaram os dados de temperatura mínima do ar, em médias por estação do ano (Tabela 2) pôde-se verificar que não houve diferença significativa pelo teste $t$, entre os pontos amostrais, sendo que o ponto 1 do sistema consorciado apresentou valores ligeiramente superiores ao cultivo a 
pleno sol $\left(0,1\right.$ a $\left.0,3^{\circ} \mathrm{C}\right)$ e ao ponto 2 do sistema consorciado $\left(0,2\right.$ a $\left.0,3^{\circ} \mathrm{C}\right)$, dependendo da época do ano. Analisando-se a evolução diária da temperatura do ar nos quatro episódios selecionados (Figura 5) constatou-se, para os valores de temperatura mínima do ar, a mesma tendência ao se analisar os dados estacionais, com diferenças não superiores a $0,1^{\circ} \mathrm{C}$ entre os pontos amostrais do sistema consorciado e o cultivo a pleno sol.

Com relação à temperatura média do ar constatada nos diferentes pontos de amostragem e se tomando como base todas as estações do ano analisadas (Tabela 2), notou-se ausência de diferença significativa entre os sistemas de produção, embora tenham sido verificadas médias superiores em 0,1 a $0,3{ }^{\circ} \mathrm{C}$ no ponto de amostragem 2 do sistema consorciado em relação ao cultivo a pleno sol e 0,1 a $0,2{ }^{\circ} \mathrm{C}$ em relação ao ponto de amostragem 1 do sistema consorciado. Analisando-se a média anual no cultivo a pleno sol, a temperatura foi de $22,7^{\circ} \mathrm{C}$, enquanto no cultivo consorciado foi de 22,8 e $23,0^{\circ} \mathrm{C}$ respectivamente, nos pontos de amostragem 1 e 2 do sistema consorciado.

Miguel et al. (1995) obtiveram, em um sistema arborizado de café com grevílea, com quatro anos de idade, em Varginha, MG, média anual da temperatura média do ar semelhante no sistema arborizado $\left(23,3^{\circ} \mathrm{C}\right)$ em relação ao cultivo a pleno sol $\left(23,2^{\circ} \mathrm{C}\right)$; quando o sistema estava com catorze anos, esses autores encontraram valores inferiores de temperatura média do ar no sistema arborizado $\left(21,9{ }^{\circ} \mathrm{C}\right) \mathrm{em}$ relação ao monocultivo $\left(23,5^{\circ} \mathrm{C}\right)$, evidenciando a influência do porte das árvores nas condições microclimáticas dos cultivos, semelhante ao encontrado com Barradas \& Fanjul (1986), no México.

\section{Umidade do ar}

Assim como na temperatura média do ar, notou-se que a umidade relativa não variou quando comparados os cultivos de café a pleno sol e consorciado (nos dois pontos amostrais). Considerando-se todo o período de amostragem, verificouse que a média da umidade relativa foi $69 \%$ para todos os pontos amostrais (Tabela 3 ).

Também se notou uma sazonalidade da umidade relativa, assim como nos casos da radiação solar e da temperatura do ar. As maiores médias foram observadas no período de verão (cerca de 78\%), sendo que a partir dos meses de outono e inverno, quando se observou ausência de chuvas significativas na área experimental (Figura 2A), notando-se os menores valores médios (cerca de $58 \%$ ).

Conforme a Tabela 2, os valores de temperatura no período diurno e, conseqüentemente, os valores de temperatura máxima para o período de outono, foram significativamente maiores no ponto de amostragem 2 do cultivo consorciado em relação ao cultivo a pleno sol, em função de que se observou uma mudança no comportamento da umidade relativa entre o ponto de amostragem 2 do sistema consorciado em relação ao cultivo a pleno sol durante os meses do outono e inverno, em relação ao período de primavera-verão, com valores superiores no cultivo a pleno sol.

Para todo o período de amostragem, o DPV médio foi de $1,03 \mathrm{kPa}$ para o cultivo a pleno sol, de 1,03 e 1,08 $\mathrm{kPa}$ para
Tabela 3. Médias da umidade relativa do ar (\%), déficit de satur ação de vapor d'água $(\mathrm{kPa})$ e pressão atual de vapor d'água $(\mathrm{kPa})$ e valores do teste t de compar ação de médias, em cultivo de café a pleno sol e em diferentes pontos amostrais de cultivo café cons orciado com bananeira 'Prata Anã', em Mococa, SP

\begin{tabular}{|c|c|c|c|c|c|c|}
\hline \multirow{2}{*}{ Época } & \multirow{2}{*}{$\begin{array}{l}\text { Pleno } \\
\text { sol }\end{array}$} & \multicolumn{2}{|c|}{ Consorciado } & \multicolumn{3}{|c|}{ Valor de $t$} \\
\hline & & P1 & P3 & Pleno sol - P & Pleno sol - P3 & P1 - P3 \\
\hline & \multicolumn{6}{|c|}{ Umidade relativa do ar (\%) } \\
\hline Primavera & 71,0 & 70,2 & 72,0 & $0,39^{\text {ns }}$ & $0,55^{\mathrm{ns}}$ & $0,95^{\mathrm{ns}}$ \\
\hline Verão & 78,5 & 78,0 & 78,3 & $0,35^{\mathrm{ns}}$ & $0,12^{\mathrm{ns}}$ & $0,22^{\mathrm{ns}}$ \\
\hline Outono & 68,4 & 69,1 & 67,0 & $0,54^{\mathrm{ns}}$ & $1,19^{\text {ns }}$ & $1,72^{\mathrm{ns}}$ \\
\hline \multirow[t]{2}{*}{ Inverno } & 58,4 & 58,4 & 57,3 & $0,18^{\text {ns }}$ & $0,54^{\text {ns }}$ & $0,72^{\text {ns }}$ \\
\hline & \multicolumn{6}{|c|}{ Déficit de saturação (kPa) } \\
\hline Primavera & 1,01 & 1,01 & 1,03 & $0,25^{\mathrm{ns}}$ & $0,26^{\mathrm{ns}}$ & $0,26^{\mathrm{ns}}$ \\
\hline Verão & 0,80 & 0,80 & 0,84 & $0,01^{\text {ns }}$ & $0,75^{\mathrm{ns}}$ & $0,77^{\mathrm{ns}}$ \\
\hline Outono & 1,06 & 1,05 & 1,17 & $0,25^{\mathrm{ns}}$ & $2,24^{*}$ & $2,45^{\star *}$ \\
\hline \multirow[t]{2}{*}{ Inverno } & 1,26 & 1,26 & 1,32 & $0,01^{\text {ns }}$ & $0,87^{\text {ns }}$ & $0,88^{\text {ns }}$ \\
\hline & \multicolumn{6}{|c|}{ Pressão atual de vapor (kPa) } \\
\hline Primavera & 1,98 & 2,02 & 1,97 & $0,24^{\mathrm{ns}}$ & $1,23^{\text {ns }}$ & $1,47^{\mathrm{ns}}$ \\
\hline Verão & 2,28 & 2,28 & 2,30 & $0,44^{\mathrm{ns}}$ & $1,46^{\mathrm{ns}}$ & $1,74^{\mathrm{ns}}$ \\
\hline Outono & 1,77 & 1,80 & 1,77 & $0,68^{\mathrm{ns}}$ & $0,02^{\mathrm{ns}}$ & $0,66^{\mathrm{ns}}$ \\
\hline Inverno & 1,38 & 1,40 & 1,37 & $0,45^{\mathrm{ns}}$ & $0,27^{\mathrm{ns}}$ & $0,43^{\text {ns }}$ \\
\hline
\end{tabular}

o cultivo consorciado nos pontos de amostragem 1 e 2, respectivamente, verificando-se diferenças estatísticas pelo teste $t$, para o período de outono entre o ponto 2 do sistema consorciado e os outros pontos amostrais (Tabela 3 ).

Apesar da parcela consorciada apresentar, em seu ponto central de amostragem, menores valores de umidade relativa e, por conseqüência, maiores valores de déficit de saturação, quando são analisados os valores de pressão atual de vapor (Tabela 3) esta tendência não é notória, principalmente no período de verão e outono, visto que, no ponto 2 de amostragem do sistema consorciado os valores permaneceram em igualdade ou foram superiores aos do cultivo a pleno sol, embora sem diferenças estatísticas significativas. Em cultivos protegidos por quebra-ventos vários autores observaram o mesmo comportamento, como o caso de Brown \& Rosenberg (1972), Ujah \& Adeoye (1984), entre outros, sendo que esta tendência é explicada pela redução da incidência de vento (Tabela 1), que diminui a quantidade de vapor no ar adjacente ao dossel das plantas. Ainda sobre o assunto, Brenner (1996) relata que o teor de umidade sobre a superfície de cultivos entre árvores esparsas é influenciado pelo tipo de vegetação e teor de umidade do solo.

Apresenta-se, na Figura 6 a variação da pressão atual de vapor d'água (ea) nos pontos amostrais durante quatro episódios, sob condição ensolarada. No dia 8/11/2001 (Figura 6A) a pressão atual de vapor no período diurno foi sistematicamente superior no ponto amostral 2 da parcela consorciada em relação aos outros pontos de amostragem, efeito da redução da incidência de vento no centro da parcela consorciada. Para os outros episódios selecionados o comportamento da pressão atual de vapor foi semelhante para todos os pontos amostrais, segundo a Tabela 3.

Quando analisada a evolução da pressão atual de vapor para todos os pontos amostrais nos diferentes episódios 
selecionados, notam-se tendências distintas de variação ao longo dos dias amostrados. No dia 6/11/2001 (Figura 6A), em uma época úmida verificou-se uma elevação de $e a$ na parte da manhã, atingindo níveis de $2,3 \mathrm{kPa}$, com redução
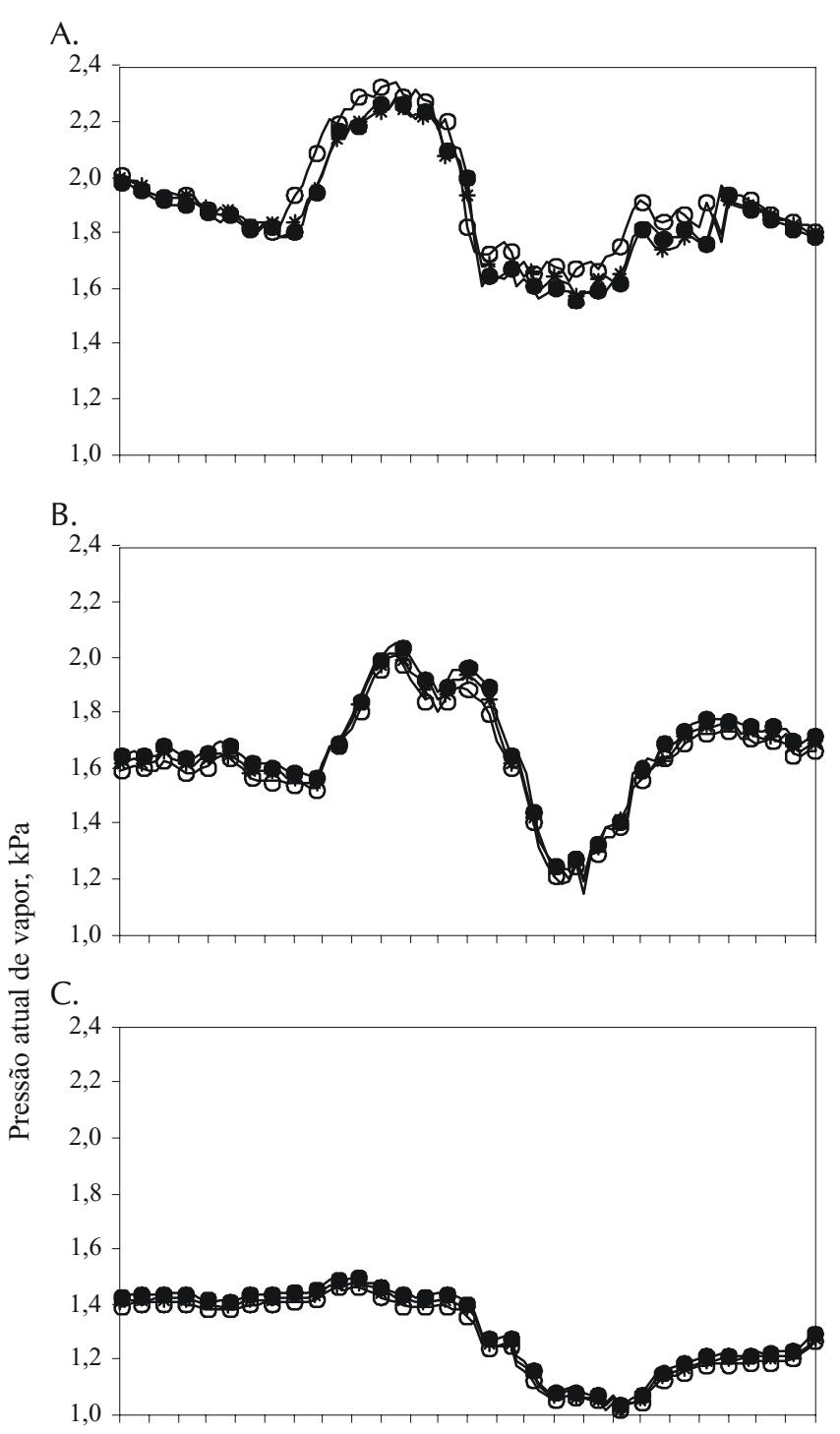

D.

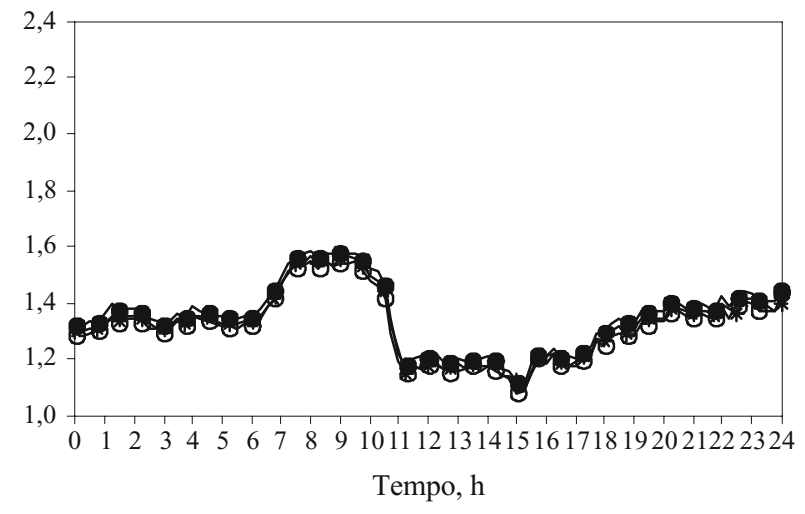

$\rightarrow$ Pleno sol - Consorciado - Ponto 1 - Consorciado Ponto 2

Figura 6. Variação dos valores horários da pressão atual de vapor d'água em cultivo de café a pleno sol e em diferentes pontos amostrais de cultivo de café cons orciado com banana 'Prata Anã ', em Mococa, SP, nos dias 6/ $11 / 2001$ (A), 16/4/2002 (B), 18/08/2002 (C) e 27/9/2002 (D) no período da tarde, e comportamento semelhante ao encontrado por Angelocci (1996) em um pomar de macieiras e por Marin (2003) em um cafezal cultivado em renque. Segundo os autores, este efeito está associado à abertura estomática, mais intensa no período da manhã, com conseqüente incremento da quantidade de vapor d'água na atmosfera, o que começa a declinar no período da tarde. Esta tendência foi menos significativa no dia 16/4/2002 (Figura $6 \mathrm{~B}$ ), quando os níveis de ea sofreram pequeno declínio às 10 horas $\mathrm{e}$, no final da tarde, atingiram valores mínimos próximos a 1,2 $\mathrm{kPa}$. Ressalta-se que em abril de 2002 a região em que se encontra o experimento já estava sob forte condição de seca.

Já a redução da pressão atual de vapor d'água ao longo do dia 18/8/2002 (Figura 6C), atingindo valores próximos a $1,0 \mathrm{kPa}$ no final da tarde, está relacionada à ação de uma massa de ar frio e seco que estava atuando sobre a região. A incidência de vento sobre os cultivos, com valor médio de $2,5 \mathrm{~m} \mathrm{~s}^{-1}$ no período diurno para o cultivo a pleno sol, contribuiu para diminuição da quantidade de vapor d'água sobre a superfície. No dia 27/9/2002 (Figura 6D), embora os valores de ea ainda fossem baixos ao longo do dia (valor máximo de 1,6 kPa), sua elevação no período da manhã foi ocasionada pela ocorrência de chuvas nos dias anteriores, o que proporcionou elevação no incremento da quantidade de vapor d'água na atmosfera.

\section{CONCLUSÕES}

1. O cultivo consorciado de café promoveu atenuação dos valores médios da radiação solar global, tendo sido mais evidente no ponto amostral, situado próximo às bananeiras.

2. Houve redução média de $48 \%$ na velocidade do vento no cultivo consorciado, que foi influenciada pela época do ano e desbaste das bananeiras.

3. Nos diferentes pontos amostrais do cultivo consorciado não se encontraram diferenças significativas em relação ao cultivo a pleno sol, para os valores de temperaturas média e mínima do ar, da umidade relativa e da pressão atual de vapor, em nenhuma época do ano.

4. A temperatura máxima no ponto central da parcela do cultivo consorciado apresentou médias superiores em relação ao cultivo a pleno sol no verão e outono, e em relação ao ponto situado próximo às bananeiras na primavera, verão e outono, cujas diferenças foram mais significativas em dias com condição ensolarada e de pouca ocorrência de vento.

\section{LITERATURA CITADA}

Angelocci, L. R. Estimativa da transpiração máxima de macieiras (Malus spp.) em pomares pelo modelo de Penman-Monteith. Piracicaba: ESALQ/USP, 1996. 103p. Tese Livre-Docência

Baggio, A. J.; Caramori, P. H.; Androcioli, A.; Montoya, L. Productiviy of southern Brazilian coffee plantations shaded by different stockings of Grevillea robusta. Agroforestry Systems, Amsterdam, v.37, n.2, p.111-120, 1997. 
Barradas, V. L.; Fanjul, L. Microclimatic characterization of shaded and open-grow coffee (Coffea arabica L.) plantations in Mexico. Agricultural and Forest Meteorology, Amsterdam, v.38, p. 101-112, 1986.

Brenner, A. J. Microclimatic modifications in agroforestry. In: Ong, C. K.; Huxley, P. (ed.). Tree-crop interactions - A physiological approach. Cambridge: University Press, 1996. cap.5, p.159-188.

Brown, K. V.; Rosenberg, N. J. Shelter-effects on microclimate, growth and water use by irrigated sugar beets in the great plains. Agricultural Meteorology, Amsterdam, v.9, p.241263, 1972.

Camargo, A. P.; Pereira, A. R. Agrometeorology of the coffee crop. World Meteorological Organization. Geneva: WMO/TD, 1994. n.615, 43p.

Camargo, M. B. P.; Camargo, A. P. Representação gráfica informatizada do extrato do balanço hídrico de Thornthwaite \& Mather. Bragantia, Campinas, v.52, n.2, p.169-172, 1993.

Caramori P. H.; Manetti Filho, J. Proteção dos cafeeiros contra geadas. Londrina: IAPAR. 1993. 27 p. Circular Técnica, n 79.

Caramori, P. H.; Ometto, J. C.; Villa Nova, N. A.; Costa, J. D. Efeitos do vento sobre mudas de cafeeiro Mundo Novo e Catuaí Vermelho. Pesquisa Agropecuária Brasileira, Brasília, v.21, n. 11, p.1113-1118, 1986.

Marin, F. R. Evapotranspiração e transpiração máxima em cafezal adensado. Piracicaba: ESALQ/USP, 2003. 118p. Tese Doutorado

Matiello, J. B.; Almeida, S. R. Sistemas de combinação de café com seringueira, no sul de Minas Gerais. In: Congresso Brasileiro de Pesquisas Cafeeiras, 17, 1991, Varginha. Resumos... Rio de Janeiro: MARA/SNPA/EMBRAPA, 1991. p.112-114.
Matiello, J. B.; Dantas, F. A. S.; Camargo, A. P. de; Ribeiro, R. N. C. Níveis de sombreamento em cafezal na região serrana de Pernambuco. Parte III. In: Congresso Brasileiro de Pesquisas Cafeeiras, 15, 1989. Resumos... Rio de Janeiro: IBC, 1989. p.182.

Miguel, A. E.; Matiello, J. B.; Camargo, A. P.; Almeida, S. R.; Guimarães, S. R. Efeitos da arborização do cafezal com Grevillea robusta nas temperaturas do ar e umidade do solo, Parte II. In: Congresso Brasileiro de Pesquisas Cafeeiras, 21, 1995. Resumos... Rio de Janeiro: PROCAFE, 1995. p.55-60

Moreira, R. S. Banana: Teoria e práticas de cultivo. Campinas: Fundação Cargill. 1987. 335p.

Pereira, A. R.; Vila Nova, N. A.; Sedyama, G. C. Evapotranspiração. Piracicaba: FEALQ, 1997, 183p.

Pezzopane, J. R. M.; Gallo, P. B.; Pedro Júnior, M. J.; Ortolani, A. A. Caracterização microclimática em cultivo consorciado café/coqueiro-anão verde. Revista Brasileira de Agrometeorologia, Santa Maria, v.11, n.2, p.293-302, 2003.

Thomaziello, R. A.; Fazuoli, L. C.; Pezzopane, J. R. M.; Fahl, J. I.; Carelli, M. L. C. Café Arábica: cultura e técnicas de produção. Campinas: IAC. 2000. 82p. Boletim Técnico n.187

Ujah, J. E.; Adeoye, K. H. Effects of shelterbelts in the Sudan Savanna zone of Nigeria on microclimate and yield of millet. Agricultural and Forest Meteorology, Amsterdam, v.33, n. 2/3, p.99-107, 1984.

Vaast, P.; Kanten, R.; Siles, P.; Dzib, B.; Franck, N.; Harmand, J. M.; Genard, M. Shade: a key factor for coffee sustainability and quality. In: Asic Conference, 20, 2004, Bangalore. Proceedings... Bangalore: ASIC, 2004. CD Rom

Vieira, S. Introdução à bioestatística. Rio de Janeiro: Elsevier. 1980. 196p. 